\title{
Influence of random shrinkage porosity on equivalent elastic modulus of casting: A statistical and numerical approach
}

\author{
*Wei Liu', Feng Lí ${ }^{1}$, Fuhua Yan ${ }^{2}$, and Hui Wang ${ }^{2}$ \\ 1. School of Mechanics, Civil Eng. \& Architecture, Northwestern Polytechnical University, Xi'an 710129, China \\ 2. No.12 Research Institute of CSIC, Xingping 713102, China
}

\begin{abstract}
Shrinkage porosity is a type of random distribution defects and exists in most large castings. Different from the periodic symmetry defects or certain distribution defects, shrinkage porosity presents a random "cloud-like" configuration, which brings difficulties in quantifying the effective performance of defected casting. In this paper, the influences of random shrinkage porosity on the equivalent elastic modulus of QT400-18 casting were studied by a numerical statistics approach. An improved random algorithm was applied into the lattice model to simulate the "cloud-like" morphology of shrinkage porosity. Then, a large number of numerical samples containing random levels of shrinkage were generated by the proposed algorithm. The stress concentration factor and equivalent elastic modulus of these numerical samples were calculated. Based on a statistical approach, the effects of shrinkage porosity's distribution characteristics, such as area fraction, shape, and relative location on the casting's equivalent mechanical properties were discussed respectively. It is shown that the approach with randomly distributed defects has better predictive capabilities than traditional methods. The following conclusions can be drawn from the statistical simulations: (1) the effective modulus decreases remarkably if the shrinkage porosity percent is greater than 1.5\%; (2) the average Stress Concentration Factor (SCF) produced by shrinkage porosity is about 2.0; (3) the defect's length across the loading direction plays a more important role in the effective modulus than the length along the loading direction; (4) the surface defect perpendicular to loading direction reduces the mean modulus about $1.5 \%$ more than a defect of other position.
\end{abstract}

Key words: random lattice model; equivalent elastic modulus; shrinkage porosity defects; casting

CLC numbers: TG143.5 Document code: A Article ID: 1672-6421(2017)02-108-13

$\mathrm{L}$ arge iron castings are widely used for "heavyduty" applications nowadays, such as wind/water generators or marine diesel engines. However, because of huge sections, complex shapes and numerous diecasts, shrinkage porosity defects cannot be totally eliminated in large castings ${ }^{[1,2]}$. In engineering, to avoid unnecessary waste, large castings with minor shrinkage defects are tolerable sometimes. But after all, shrinkage porosity is deleterious to casting components; it reduces the effective area for loading and results in stress concentration ${ }^{[3,4]}$. This conflict brings difficulties in material performance reliability evaluation and structural

\footnotetext{
*Wei Liu

Male, Ph. D., Associate Professor. His research focus is mainly on the influence of shrinkage porosity on the mechanical properties of castings and simulation methods.
}

E-mail: liuwei@nwpu.edu.cn

Received: 2016-10-30; Accepted: 2017-02-23 safety design. Therefore, it is meaningful to quantify the effective performance of castings containing shrinkage porosity defects.

Shrinkage porosity significantly affects the mechanical performance of casting structure and has been receiving considerable attention in casting industry. In early studies, shrinkage porosity was usually considered as a type of void, pore defect or porous media. Theories of porous media and minimal solid area (MSA) were applied to estimate strength and stiffness performances ${ }^{[5-7]}$. In many other investigations, the materials containing the pores defect were considered as multi-phase/composite materials. Based on the homogenization assumption and perturbation method, analytical solutions of stress concentration fields surrounding inclusions or pores were obtained ${ }^{[6-9]}$. Sakata et al. ${ }^{[10]}$ formulated stochastic characteristics of an equivalent elastic property model by a higher order perturbation-based method. Wu et al. ${ }^{[1]}$ obtained the differential expression of effective modulus variation 
using Eshelby tensor analysis. Damage factors or fracture mechanics were combined with the above theories. Some parameters, such as void volume fraction, maximal/mean pore size, defected areas, etc. were applied as damage factors to establish the empirical models for the loss of stiffness and ductility. 3D morphology of shrinkage porosity was obtained by radiographic imaging (Wan et al. ${ }^{[2]}$, Tijani et al. ${ }^{[12]}$, and Hardin $\left.{ }^{[1,16]}\right)$. Stress redistribution, ductile fracture and plastic behavior caused by shrinkage porosity were well simulated ${ }^{[13-16]}$.

However, many of the above investigations were carried out on a designated or determined shrinkage defect. Actually, the shrinkage porosity defects distributed irregularly in castings ${ }^{[1,11,17,18]}$, which means their configurations were intangible, and their shapes and spatial positions in casting were also somewhat different. Because of this inhomogeneous and random characteristic, the mechanical performances of castings with shrinkage porosity were uncertain ${ }^{[19,20]}$. Moreover, the crack growth behaviors were correlated with the probability distributions, such as the number (defect density), size, and location of defects ${ }^{[21,22]}$.

It was complicated to obtain this kind of random-defected material's mechanical function by traditional determinable methods ${ }^{[10,23]}$. To consider this random inhomogeneous defected material, some numerical simulations methods were developed, such as the cell method ${ }^{[24]}$ and lattice model ${ }^{[25,26]}$. These models were developed to describe random distribution defects. It is noteworthy that the methods mainly focused on periodic symmetry defects (in composite material) or certain distribution defects. However, different from general random inhomogeneous material, shrinkage porosity in a casting presents a random "cloud-like" configuration. Therefore, to make a more reasonable estimation of the mechanical performance for castings containing shrinkage porosity, more modeling methods should be developed to describe special random characteristics of shrinkage porosity.

In this paper, aiming at the non-homogeneous and localrandom characteristics of shrinkage porosity, we proposed an improved random lattice model algorithm to describe the arbitrary configurations of defect. The random characteristics of defect area fraction, shape, position were well simulated. The effects of random shrinkage porosity on the effective modulus and the stress concentration factor were numerically studied by a statistical approach. The investigation provided a new method to estimate effective mechanical performances and safety criterions for casting structures containing shrinkage porosity.

\section{Experiment}

\subsection{Material and specimen}

QT400-18(ISO: 400-18) is a type of nodular cast iron material applied in heavy diesel engines engineering. It is often used for engine block or crankshaft, etc. Restricted by the current solidified technology, shrinkage porosity defect is yet not completely avoided in heavy castings. In engineering, the surface/exposed defects can be repaired by a welding technique to extend their service life. But some of the shrinkage defect lies hidden in castings and is difficult to access. In practice, a low percentage of shrinkage porosity in a large casting is sometimes tolerated.

To investigate the influences of shrinkage porosity on the mechanical performance of QT400-18, specimens containing shrinkage were designed firstly. For heavy casting structures, in general, the size on the vertical direction of loading is far lower than the size on the loading direction, so the problem can be converted into plane stress analysis. In the paper, only the loadcase of plane stress was discussed, and a plate-shaped specimen was applied. Shrinkage porosity was prefabricated in the center of cast iron ingots firstly, then the ingots were cut into a number of pieces from the transverse direction. For details on this process, please refer to our previous work ${ }^{[18]}$. Each piece then was machined into the tensile test specimen. The dimensions of the specimen are shown in Fig. 1.

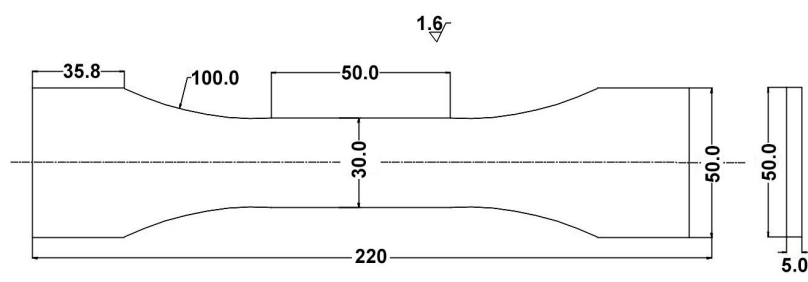

Fig. 1: Dimensions of QT400-18 specimen containing shrinkage porosity (unit: $\mathrm{mm}$ )

Figure 2 shows the shrinkage porosity defect exposed on the gauge surface of different specimens ${ }^{[18]}$. On the macroscopic view, the distribution, size and shape of the shrinkage porosity regions are totally irregular in different specimens. Shrinkage porosity shows a special configuration: random "cloud-
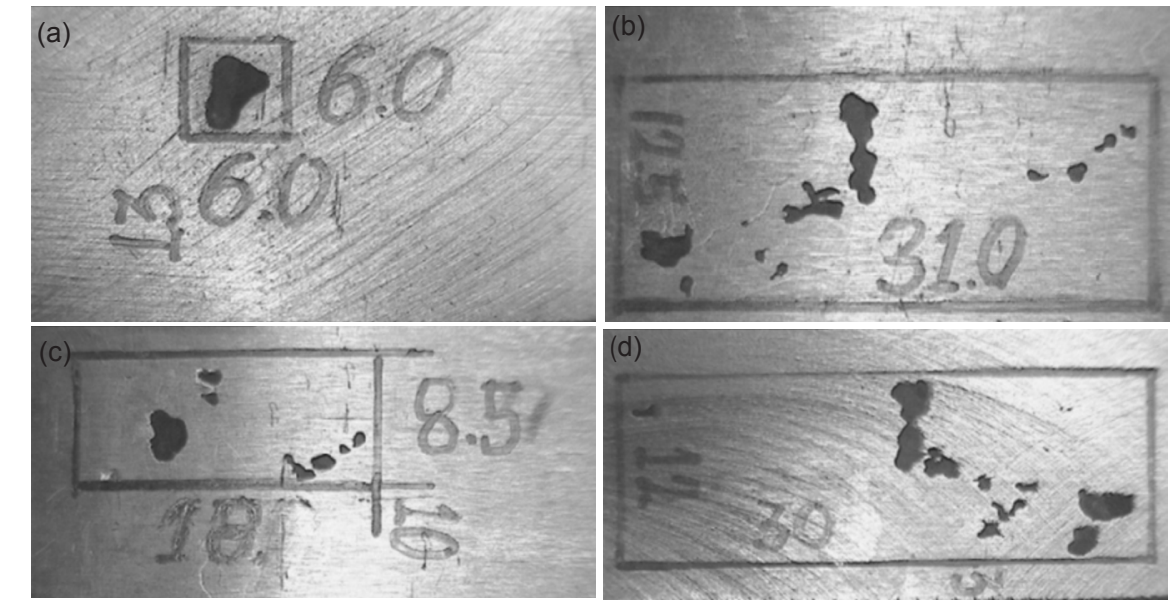

Fig. 2: Shrinkage porosity exposed on gauge surface of several specimens: defect distributed irregularly in castings 
like" aggregations combining with sporadic random scatters, rather than periodic randomness or a certain type of random distribution function. In order to help readers to recognize the size of the shrinkage porosity region, an auxiliary wire-frame is used to mark the entire region of the porosity defect (unit: $\mathrm{mm}$ ).

\subsection{Experimental process}

In order to obtain the tensile properties of the above specimens containing shrinkage porosity, monotonic tensile tests were carried out on Instron-5567 tensile-testing machine at room temperature. The tests loading was executed by displacement control mode, the loading rate was $1 \mathrm{~mm} \cdot \mathrm{min}^{-1}$. The strain extension of the gauge section was obtained by an MTS extensometer. Five shrinkage specimens and a non-defect specimen were tested.

\section{Experiment results}

Shrinkage porosity plays a leading role on the failure of the defect specimen, as shown in Fig. 3. The fractures all of defect specimens take place in the shrinkage porosity region under the load case of uniaxial tension.

Figure 4 displays the tensile stress-strain curves of specimens. Compared with the non-defect specimen, both the strength and ductility are weakened if the specimens contain shrinkage porosity. Moreover, on a shrinkage defect specimen, the original post-yield hardening phenomenon seen on the non-defect specimen is not observed

In order to identify the influence of shrinkage extent on mechanical properties, shrinkage area percentage $(\varphi)$ is applied to characterize shrinkage porosity extent in the plane. Here, $\varphi$ is the area fraction between the shrinkage porosity region and the entire load-bearing area, defined as $\varphi=A_{d} / A_{t}$, where $A_{t}$ is the whole area of gauge section, $A_{d}$ is the shrinkage porosity area. The effective elastic module, tensile stress and failure strain of tested specimens with different shrinkage rates are listed in Table 1. In the table, the values of $\varphi$ for specimens No. 1 and No. 2 are the surface shrinkage area percentages; shrinkage porosity defects of No. 3 to No. 5 are buried inside the specimens. Actually, the area of shrinkage porosity is various in the thickness direction. Therefore, $\varphi$ is only an approximation for describing shrinkage extent.

Experimental results showed that when the surface shrinkage rate was less than $5 \%$, the mean effective modules reduced about $13 \%$, and the mean ultimate stress decreased about $35 \%$. The ductility capacity decreased sharply, the mean failure strain reduced nearly $80 \%$. These performances were greatly weakened even though the specimen contained a small percentage of shrinkage porosity features.

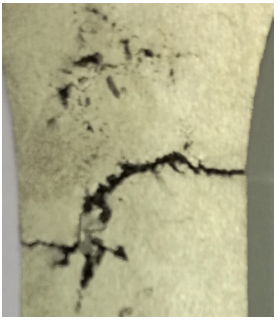

$1 \#$

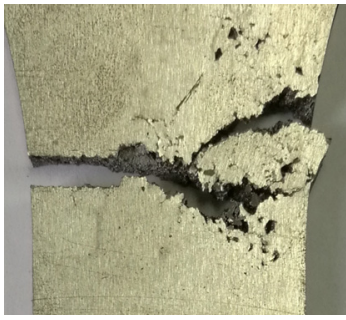

2\#

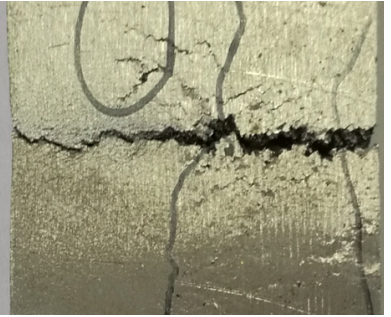

3\#

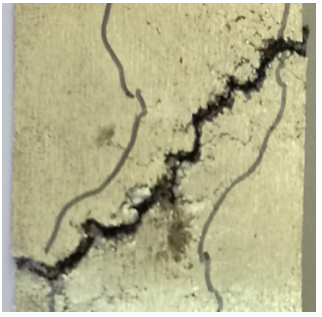

4\#

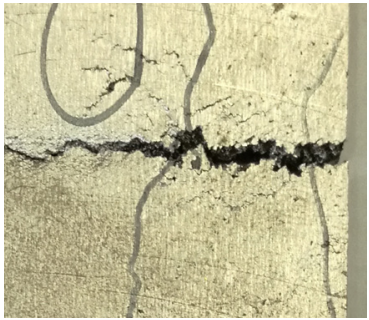

$5 \#$

Fig. 3: Fractures take place in shrinkage porosity region under uniaxial tensile loading

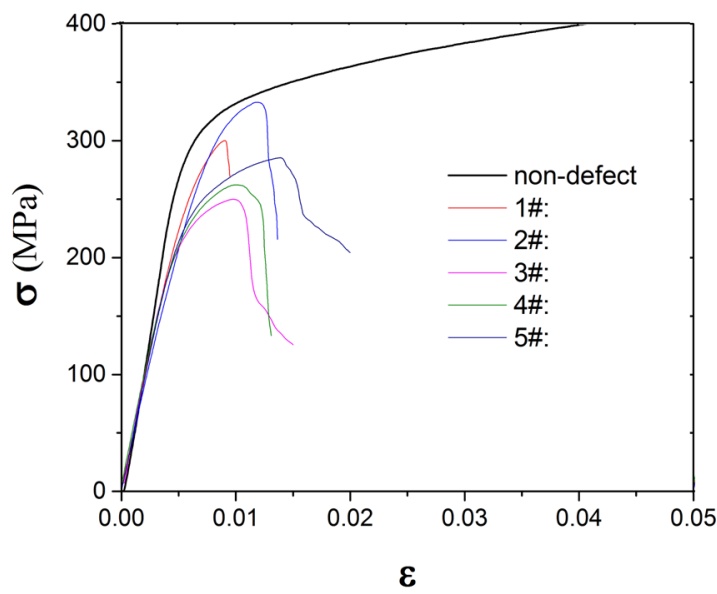

Fig. 4: Tensile stress-strain curves of specimens containing shrinkage porosity

\section{Improved random lattice method}

\subsection{D modeling method for a casting containing shrinkage porosity}

Generally, the shrinkage porosity defect in a casting has a threedimensional appearance. In order to simplify the problem, a 2D modeling method for a casting containing shrinkage porosity is proposed. Firstly, a slice containing shrinkage porosity is selected from the casting, this slice plane is regarded as a representative plane (or gauge plane), and used to evaluate the damage caused by the shrinkage porosity defect. Secondly, a rectangular wire-frame is used to mark the entire region of the porosity defect on the gauge plane, ensuring that the rectangle's width edge is perpendicular to stress direction. The 2D modeling method is applicable to the following stress conditions: plane stress, plane strain and principal stress. The selection method for slice plane and rectangle are shown in Fig. 5. 
Table 1: Tensile performances of specimens containing shrinkage porosity defect

\begin{tabular}{ccccc} 
specimen & $\boldsymbol{\varphi}$ & Effective modules & Ultimate stress & Failure strain \\
\hline 1 & $3.9 \%$ & $123.5 \mathrm{GPa}$ & $300 \mathrm{MPa}$ & 0.00658 \\
2 & $2.7 \%$ & $135.2 \mathrm{GPa}$ & $332 \mathrm{MPa}$ & 0.0095 \\
3 & Inner defect & $141.9 \mathrm{GPa}$ & $249 \mathrm{MPa}$ & 0.0103 \\
4 & Inner defect & $130.6 \mathrm{GPa}$ & $262 \mathrm{MPa}$ & 0.00911 \\
5 & Inner defect & $133.1 \mathrm{GPa}$ & $284 \mathrm{MPa}$ & 0.0139 \\
6 & Non-defect & $148.5 \mathrm{GPa}$ & $443 \mathrm{MPa}$ & 0.0624
\end{tabular}

(1) In plane stress condition, taking a casting thick-rod as an example, the casting subjected to in-plane loading acting in its own plane, as shown in Fig. 5(a), the gauge plane is a uniaxial stress plane containing shrinkage porosity, the rectangle's height edge is selected as perpendicular to the stress direction.

(2) In the plane strain condition, such as a long body casting shown in Fig. 5(b), which is subjected to transverse loading and its cross section and loading do not vary significantly in the longitudinal direction, a small thickness in the loaded area containing defect can be treated as the gauge plane. The rectangle's height edge is selected as perpendicular to the stress direction.

(3) In the principal stress condition, a point inside the casting is subjected to an arbitrary stress state. The principal stress tensors can be obtained when the basis is changed in such a way that the shear stress components become zero. As shown in Fig. 5 (c), the gauge plane is maximal principal stress plane containing shrinkage porosity, the rectangle's height edge is selected as perpendicular to the maximal principal stress direction.

\subsection{Lattice method}

The lattice method is a numerical method for describing the heterogeneous material. Here, to explain its basic idea, we take an arbitrary specimen containing certain shrinkage porosity , shown as the black region in Fig. 6(a). We firstly discretize the specimen into a number of lattice elements with the same size by FEM, as shown in Fig. 6(b). The material property of each element is treated as homogeneous elasticity. The difference is, the defect part in the specimen can be defined by specifying the defect material property (that is different from the base material). If the selected defect elements in Fig. 6(b) are close to the shrinkage porosity configuration showed in Fig. 6 (a), then an approximate equivalent numerical model of the specimen containing a shrinkage porosity is established.

In the traditional lattice model, the randomness of medium

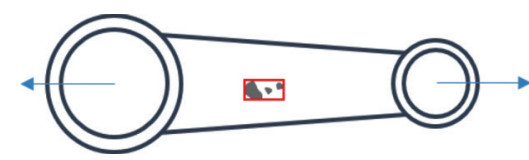

(a) Plane stress

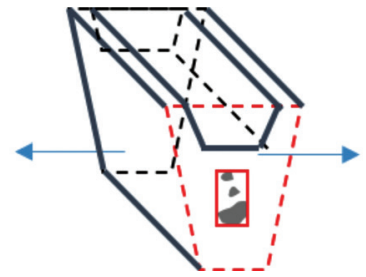

(b) Plane strain

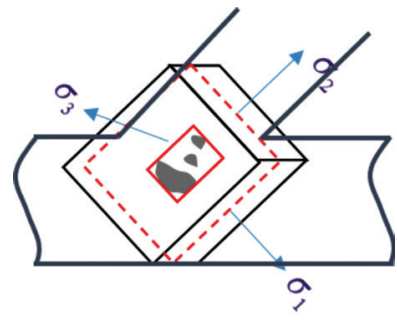

(c) Principal stress

Fig. 5: 2D modeling method: selection of gauge plane and marked rectangle

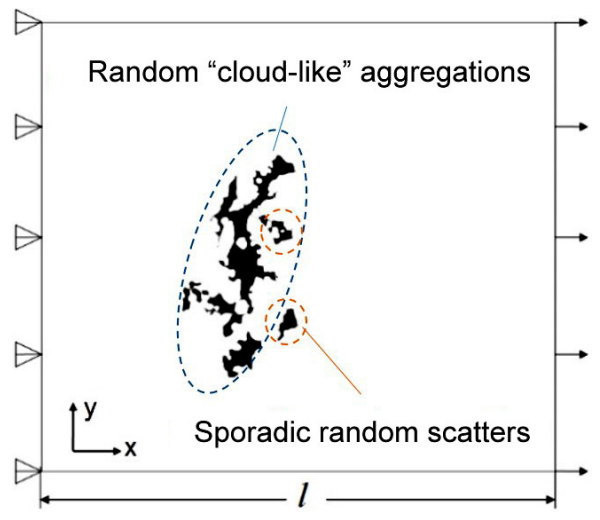

(a) A specimen containing shrinkage porosity

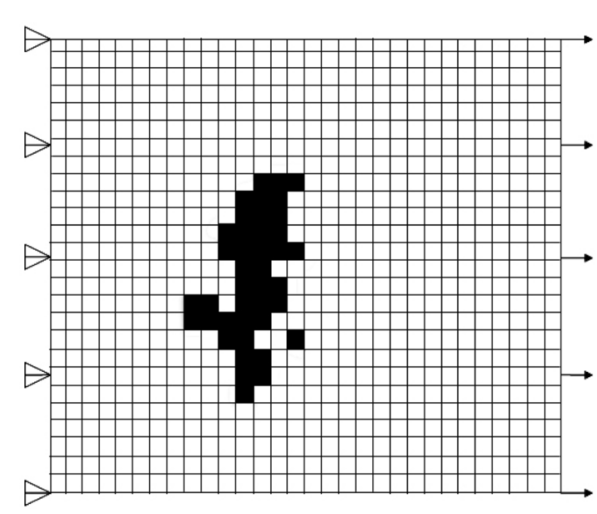

(b) An equivalent numerical specimen

Fig. 6: Sketch image of a lattice model for a specimen containing shrinkage defect 
is carried out by specifying elements number according to a random distribution function. For example, the numbers of the defect elements are randomly generated according to the Normal distribution or Weibull distribution ${ }^{[20,25,26]}$, by this method, the defect elements randomly scatter in the base material uniformly without any aggregation. However, different from the traditional random defect material, as shown in Fig. 2 and Fig. 3, the shrinkage porosity defect elements randomly gather like "clouds", and some sporadic shrinkage defect elements are scattered points, so the distribution of shrinkage defect does not obey a certain distribution function. Moreover, the size, shape, location, etc. of shrinkage porosity are also uncertain, which will result in a final uncertain comprehensive mechanical performance. Traditional random lattice modeling cannot completely reflect this special randomness of the shrinkage porosity.

\subsection{Random distribution simulation of shrinkage defects}

In order to describe the special random characteristics of shrinkage porosity, the traditional random lattice model is improved in this paper. Figure 7 shows the three steps to carry out the procedures: (1) random area and shape; (2) random distribution; (3) random position in gauge section.

\section{(1) Random area and shape}

For a random planar shrinkage porosity defect, a rectangular envelope can be applied to approximately cover the whole region of shrinkage porosity (the rectangular wire-frame is shown in Fig. 2). For a single numerical modeling, the first step is to generate a rectangle on a gauge plane of a casting containing shrinkage porosity. We appoint this rectangle to accommodate the whole defect region, and assume that there is no shrinkage defect outside the rectangle. By this simplification, the defect's area is the approximate area of rectangle, and the defect's shape is the approximate length-width ratio of the rectangle.

As shown in Fig. 7, this rectangle is an envelope region for the whole shrinkage porosity on its gauge plane. Here, a group of $m \times n$ grids/lattices elements are applied to quantify this rectangle: $m$ is the row number and $n$ is the column number, the rectangle can be expressed as an array of $R(m, n)$, and all of the defect elements will be included in these $m \times n$ elements.

Repeated sampling can be carried out, for a random shrinkage porosity defect in casting, this enveloping rectangle is also random. The values $m$ and $n$ will be generated by random number generator, and they are two random round numbers. Therefore, for different numerical samples by multiple sampling method, many samples containing different rectangles will be obtained. The area and shapes of these rectangles are random; because the values of $m$ and $n$ are random, then the area and shapes of random shrinkage porosity defect are random.

\section{(2) "Cloud-like" distribution}

Actual shrinkage porosity defect does not fill all of the above rectangle region, but presents a certain "cloud-like" distribution in the rectangle region. The second step is to pick some random elements in the above rectangle and assign defect attributes. The selected elements should reflect this special morphology. Figure 8 shows the defect distribution difference between the traditional lattice model and shrinkage porosity. In the traditional lattice model, the defect element presents point scatter distribution, as in Fig. 8(a), but shrinkage porosity presents as random flake distribution combined with a few scattered points, as shown in Fig. 8(b). Therefore, the defect elements selection method for shrinkage porosity is also different from the traditional lattice model. The actual difference is that the defect elements in Fig. 8(a) are chosen individually and discretely, but the defect elements in Fig. 8(b) are multiple (sometimes zero or one element, depending on generated random number during numerical simulation) and continuous.

Figure 9 shows the principle of defect elements selection for shrinkage porosity, we call it a "flake-pick up" method. The selecting starts from the first row of the rectangle region: select a random element (element number is $\varepsilon$, this number is randomly generated) in the row, and this element is the initial defect

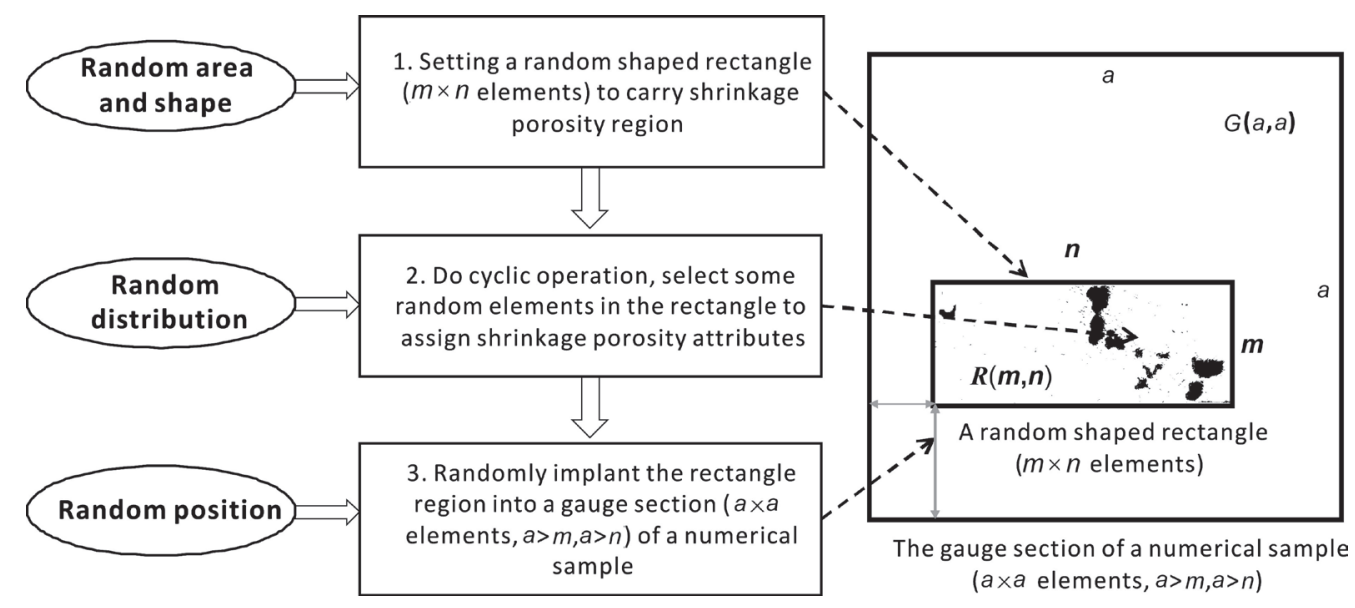

Fig. 7: Three steps to simulate a random shrinkage porosity defect. The first step is setting a random shaped rectangle to accommodate the whole shrinkage porosity region 
element in row 1 . Then select $\beta$ elements after the initial defect element, $\beta$ value is also randomly generated, then the defect elements in the first row are selected.

The above selection method in row 1 can be carried out in other rows of rectangle. An improved cyclic selecting algorithm is presented in Fig. 10 to realize this target.

The procedures are briefly summarized as follows:

(1) All the above elements $R(m, n)$ are numbered in FEM software.

(2) Start from the first row of $R(m, n)$, and the first row is set as the current row $j$ (that is $j=1$ ). A random round number $\varepsilon$ is firstly generated by a random number generator, here, $\varepsilon$ is required to be less than the column number, that is $\varepsilon<n$.

(3) In the current row, select the $\varepsilon$ th element from left to right, that is $R(\varepsilon, 1)$ in the rectangle region, $R(\varepsilon, 1)$ is the initial defect element in the row 1.

(4) Another 2D-array is defined to hold the selected defect elements in the Step 3 process, this new array is called $S(p, q)$, where $p$ and $q$ are the row number and column number in the new array, respectively. That is, the above initial defect element $R(\varepsilon, 1)$ is labeled as $S(1,1)$ in the new array, and the element with the number $S(1,1)$ is an initial defect unit on the current row. Another role of $S(p, q)$ is to count the amount of the selected number.

(5) Determine the position of the column (the column number) of the initial defect element in the current row. This can be carried out by residue arithmetic, here, we assume that the obtained column number is $k$.

(6) Another round number, $\beta$ is generated, but here, $\beta$ is a random round value in the closed interval of $(0, n-k)$, that is $\beta=$ [rand $(0, n-k)]$, the symbol [ ] denotes the rounding operation.

(7) Select the $\beta$ subsequent random elements after the initial defect element $R(\varepsilon, 1)$, these $\beta+1$ elements are the defect elements in the current row 1 , as shown in Fig. 10 . If $\beta=0$, there is only one defect element in the current row; if $\beta=n-k$, the defect elements continue until the end of the current row. The newly selected elements are then stored in the array $S(p, q)$ again, that is $S(2,1), S(3,1), \ldots, S(\beta+1,1)$, as shown in Fig.11

(8) Make a judgment: is the current row $j$ equal to $m$ ? ( $m$ is the maximal row number of the rectangle). If not, then the current row number is $j$ plus 1 and update to the new current row (that is the new current row is $j=j+1$ ), then repeat the above procedures from (2) to (7). We perform the same algorithm process on each row in the rectangle $R(m, n)$, then a certain number of elements are selected as the defected elements, until the current row rectangle

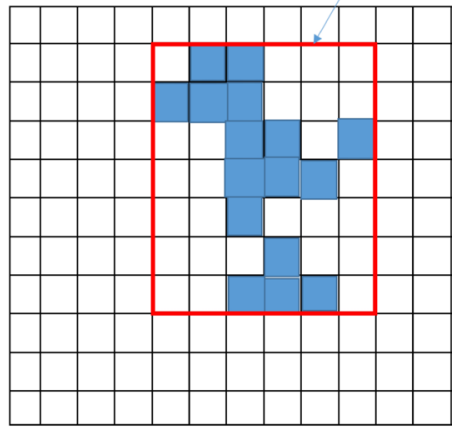

(b)

\section{Base material $\square$ defect material} traditional lattice model: (a) traditional lattice model: point scatters, (b) shrinkage porosity: flake distribution combined with few point scatters

\section{Rectangle}

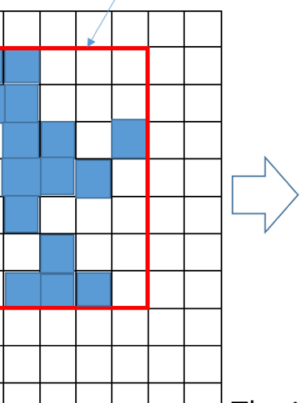

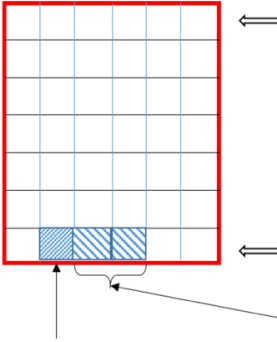

The initial element (the $\varepsilon$ th number in row 1 )
$\Longleftarrow \quad$ End at the last row

Then row number+1 Do cyclic algorithm Do cyclic algorithm Start from the first row

The subsequent continuous elements ( $\beta$ elements)

Fig. 9: Sketch diagram of shrinkage porosity elements selection method

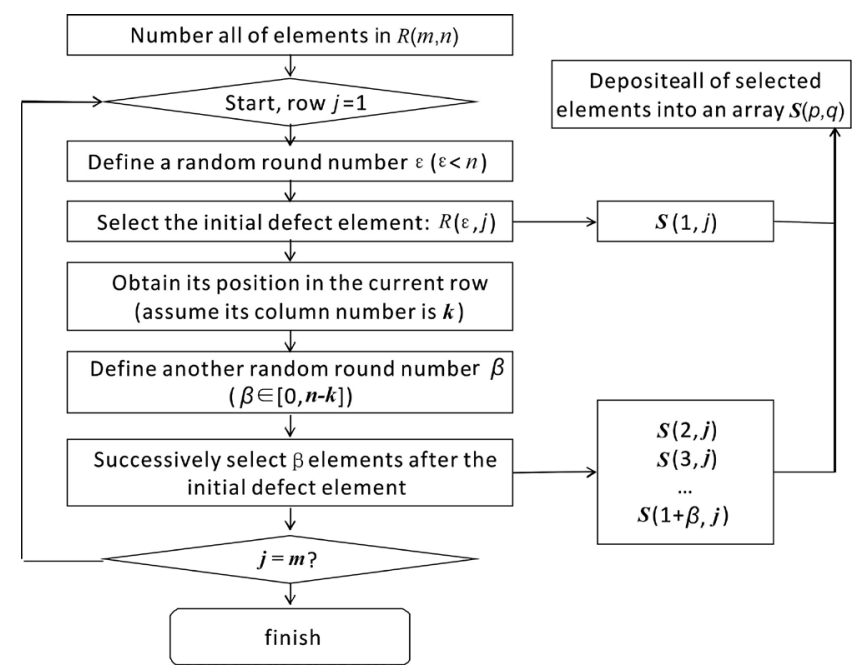

Fig. 10: Flow chart of selecting random elements in the rectangle 


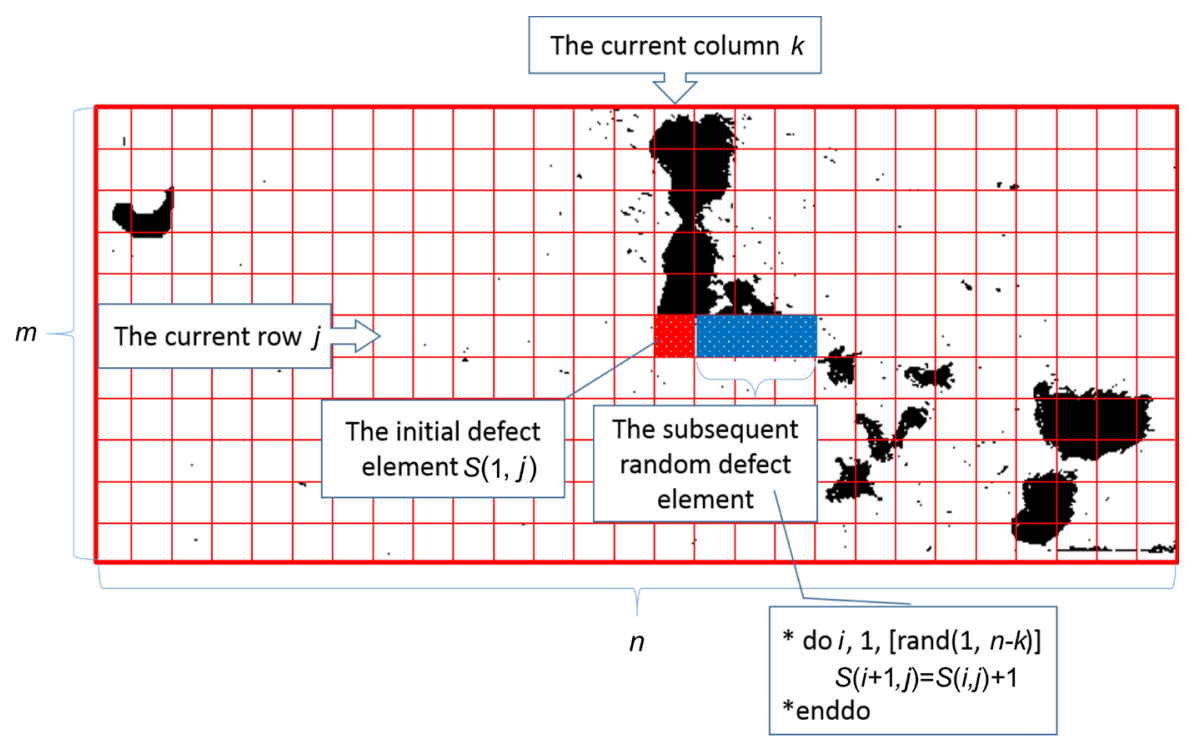

Fig. 11: Improved lattice model algorithm for generating a random shrinkage porosity defect in FEM software

number is up to $m$.

(9) If the judgment result is Yes in Step (8), stop the loop and finish the whole second step.

The above procedures are the algorithm schemes for the second step. By now a collection of shrinkage porosity elements $S(p, q)$ have been established randomly in the rectangle $R(m, n)$. The material properties of this elements collection could be assigned as the specified defect attributes.

\section{(3) Random position in gauge section}

The above two steps have constructed a random rectangle and its interior configuration of defect region. From Fig. 2 and Fig. 3, it can be seen that the above rectangle region is a part of a specimen or structure. It is important to note that the position of the shrinkage porosity defect in the gauge section is also random. The third step is to implant the rectangle region into a gauge section of a specimen randomly. We call the third step random-placement. The sketch diagram of this step is displayed

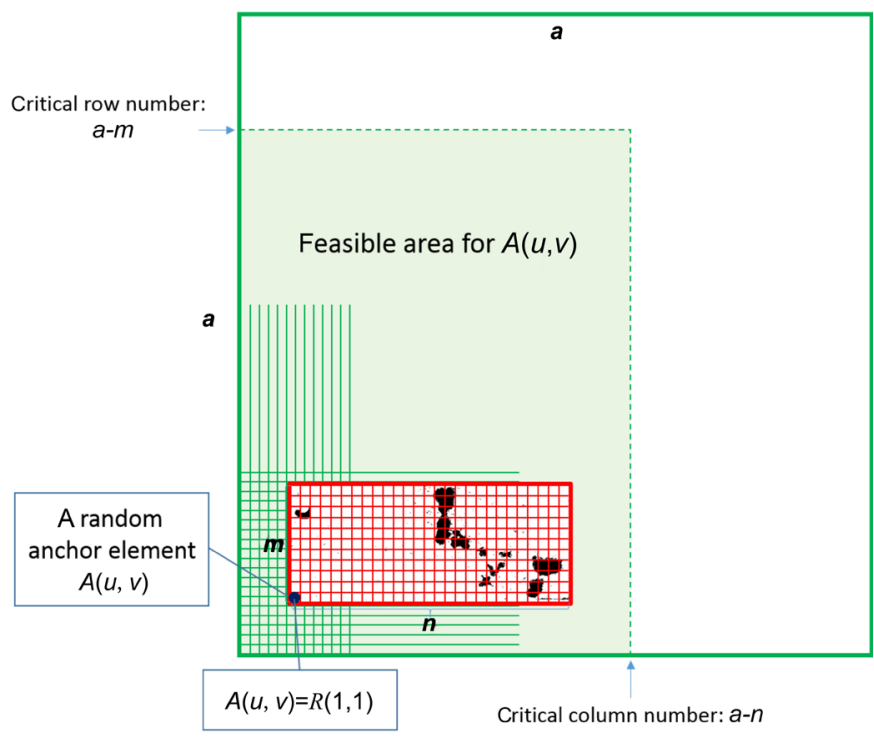

Fig. 12: Sketch diagram of implanting the rectangle region into the gauge section $G(a, a)$ in Fig. 12, and its detailed procedures are presented as follows:

The gauge section of casting is assumed as a square with elements $\mathrm{a} \times \mathrm{a}$, written as $G(\mathrm{a}, \mathrm{a}),(\mathrm{a}>m, \mathrm{a}>n)$. So the main purpose of this step is implanting the above rectangle region $R(m, n)$ into element grids of $G(\mathrm{a}, \mathrm{a})$ randomly.

To avoid the rectangle region overflow from $G(\mathrm{a}, \mathrm{a})$ grids, the initial element of rectangle region, that is $R(1,1)$, should be located in the graphic feasible area as shown in Fig. 12. Therefore, to ensure the whole rectangle $R(m, n)$ is included by the specimen $G(\mathrm{a}, \mathrm{a})$, an anchor element is specified. The location of the corresponding anchor element (called $A(u, \mathbf{v})$ ) is randomly selected from the feasible area in Fig. 12. By this way, the randomness for the position of shrinkage porosity is well described. An inhomogeneous numerical sample containing random shrinkage porosity is established.

All the above three steps can be carried out in FEM software.

For repeated sampling, many different random numbers of $m, n, \varepsilon, \beta, u, v$ would be generated. In this way, the shape, position, and area of different shrinkage porosity defects in a gauge plane are all random variable, and then a series of numerical specimens containing random shrinkage porosity can be obtained. Figure 13 displays some numerical random samples with shrinkage porosity generated by the proposed improved lattice model algorithm.

Shrinkage porosity defects sometimes exist in different parts of a casting or different castings; their shapes, areas and positions are random. Our investigation addresses how to make a general estimation for mechanical performance for a casting containing a certain shrinkage porosity. We have proposed the above improved lattice model algorithm, where a large number of samples can be generated, these numerical samples are regarded as including a certain random shrinkage porosity as far as possible, and actual defect configuration is close to one of these samples. 

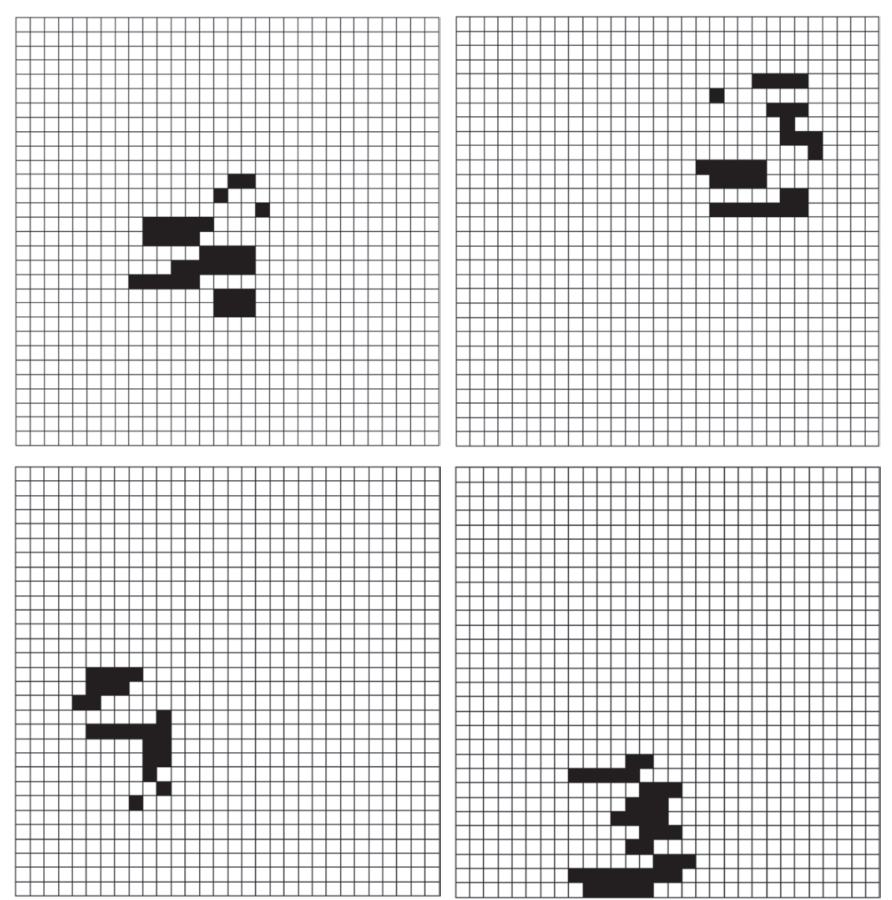

Fig. 13: Some random shrinkage porosity specimens generated by the improved lattice model algorithm

\subsection{Equivalent elastic modulus and stress concentration factor}

The paper focuses on the influence of shrinkage porosity on the equivalent elastic modulus of a casting structure. Equivalent properties are the macroscopic properties of inhomogeneous materials. The simulation of inhomogeneous defects is carried out under some approximate assumptions. Compared with the traditional lattice model, the only difference is the choice of defect elements. The other mechanics calculation methods are consistent with the traditional lattice model.

According to the Eshelby equivalent inclusion theory ${ }^{[27]}$, when the eigenstrain is homogeneous (for the elastic element) or when the external load is uniform (for inhomogeneous defect inclusions), the elastic field inside the inclusion element is also uniform. This equivalent inclusion theory becomes the basis of later lattice models and effective elastic modulus calculations. Therefore, only the material's elastic stage is discussed, in the above numerical specimen model. When analyzing the effective modulus, the lattice model assumes that every element is treated as homogeneous elasticity, that is $\sigma=E \varepsilon$, and the selected defect elements are assigned with different material properties.

Because of its unsound morphology, shrinkage porosity reduces the effective loading performance, but its loading is not totally lost. Therefore, the elastic modulus of defect elements is assumed to be less than that of the base material. The defect elements are treated as inclusions in the base material, and the relations between the nodes of each element and the deformations of adjacent elements are according to the uniform elasticity laws. The calculated boundary condition is the simplest loading method: in the loading direction, one side is the fixed constraint, the other side is applied the force load, as shown in Fig. 14. This boundary and the loading condition

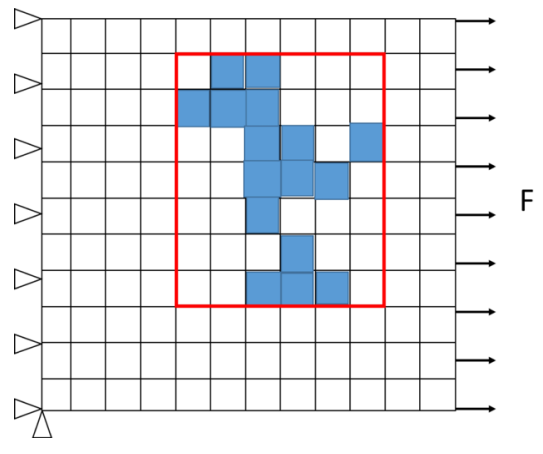

Fig. 14: Boundary and the loading condition for numerical simulations

satisfy the hypothesis of the equivalent inclusion theory.

The effective modulus is specially focused in this paper. In elastic stage, the macro equivalent stress $\sigma$ and equivalent strain $\varepsilon_{x}$ along $x$ direction (in this paper, only the uniaxial loading case is discussed, and $x$ direction is the loading direction). The effective elastic modulus $E_{\mathrm{e}}$ and Poisson's ratio $V_{\mathrm{e}}$ can be calculated as follows:

$$
E_{\mathrm{e}}=\frac{\bar{\sigma}_{x}}{\bar{\varepsilon}_{x}}, v_{\mathrm{e}}=\frac{\bar{\varepsilon}_{y}}{\bar{\varepsilon}_{x}}
$$

where $\bar{\varepsilon}_{x}, \bar{\varepsilon}_{y}$ are the mean strain of $x, y$ axis, respectively. The value of $\bar{\varepsilon}_{x}$ can be determined by:

$$
\bar{\varepsilon}_{x}=\frac{\Delta x}{L_{x}}
$$

where $\Delta x$ is the deformation (along $x$ direction) of specimen, and $L_{x}$ is the length of specimen on the $x$ axis. Similar to the definition of $\bar{\varepsilon}_{x}$, the mean strain on $y$ axis can be written as:

$$
\bar{\varepsilon}_{y}=\frac{1}{n_{x}} \frac{1}{L_{y}} \sum_{i, j=1}^{n}\left(u_{i j}\right)_{y} \mathrm{~d} y
$$

where $\left(u_{i j}\right)_{y}$ is the $y$ direction of element at coordinate $(i, j), L_{y}$ is the length of specimen on the y axis, $n_{x}$ is the number of element along the $x$ axis.

Here, the mean stress is calculated as:

$$
\bar{\sigma}_{x}=\frac{1}{n} \sum_{i=1}^{i} \sum_{j=1}^{j} \sigma_{i j}
$$

where $\sigma_{y}$ is the stress of element at coordinate $(i, j), n$ is the total number of elements.

In this paper, a stress concentration factor (SCF) is used to represent the location of shrinkage porosity where the stress is concentrated. It is defined as the ratio of the maximum stress $\left(\sigma_{\max }\right)$ to a reference stress $\left(\sigma_{\text {ref }}\right)$ of the gross cross-section:

$$
S C F=\frac{\sigma_{\max }}{\bar{\sigma}_{r e f}}
$$

where $\sigma_{\max }$ is the maximal stress in a specimen containing shrinkage porosity, $\sigma_{\text {ref }}$ is the mean stress of a non-defect specimen under the same loading condition. 


\subsection{Statistical method of effective mechanical properties}

The randomness characteristics of shrinkage porosity will introduce a great uncertainty on the mechanical performance of a casting structure. In order to quantify the influences of this randomness, many numerical samples should be produced. All of the numerical samples can be calculated by FEM. Through the above sampling and numerical simulations of random defect specimens, the stress, deformation results of all numerical samples containing random shrinkage porosity can be obtained. In order to give suggestions for structural safety design, statistical methods are applied to analyze these outputs (such as effective modulus, maximal stress, etc.). Histograms and distribution functions of outputs can be obtained. Finally, the integral effects or trends caused by randomness can be quantified.

\section{Influence of shrinkage porosity}

For the numerical samples, the material parameters are defined as follows: the base material of the gauge section is QT40018 , its elastic modulus is $E_{b}=184 \mathrm{GPa}$, Poisson's ratio is $V_{b}$ $=0.3$. Comparing with the base material, the microstructure of the defect region is more loose, but the loading capacity is not totally lost. Here, the mean elastic modulus of the defect region is assumed as $E_{p}=20 \mathrm{GPa}$, its variance is assumed as 0.05 .

\subsection{Area percentage of shrinkage porosity}

The area of the defect region is random and can be determined by the total number of the above defect element. Figure 15 displays the stress contour maps of two random numerical samples containing different area percent shrinkage porosities (the shrinkage percentages are $1.44 \%$ and $3.11 \%$, respectively). The shrinkage porosity defect is the high stress region when external loading applies. Maximal stress often occurs at the site of larger area pores or the site between two pores. The simulation is in agreement with the experiment phenomenon. As shown in Fig. 16, experimental results show the micro-cracks and crevasse-cracks nucleate between two shrinkage pores firstly, these cracks connect and accelerate the failure. This is an important reason for the fall of ductility for casting containing shrinkage porosity.

Actually, for a random shrinkage porosity, its stress response will be also random. So statistical trends should be analyzed based on a large number of samples. Figure 17(a) shows the distribution of stress concentration factor $(\mathrm{SCF})$ for the samples containing random levels of shrinkage porosity. The values of SCF are random for different shrinkage porosities, and on the whole, SCF increases with the increasing of shrinkage percentage, but the higher is the percentage, the greater the variance of SCF. It means a larger area shrinkage defect will produce a larger stress response, and its variance will also be larger. The span of stress concentration factor is from about 1.0 to 4.0. Figure 17(b) gives a SCF histogram of all numerical samples. The maximum counts frequency occurs at the value of $\mathrm{SCF}=2.0$. Therefore, the mean value of SCF produced by shrinkage porosity could be selected as 2.0 .

The effective elastic modulus $\left(E_{e}\right)$ of each numerical specimen can be calculated by Eq.(1). Figure 18(a) is the $E_{\mathrm{e}}$ calculation results of all 5000 numerical samples: the shrinkage porosity percent is $0-6 \%$. The effective elastic modulus of specimen containing random shrinkage porosity is random. When the shrinkage rate is $0-1.5 \%$, the mean value and variance of the effective modulus does not change noticeably. In particular, the value of $E_{\mathrm{e}}$ decreases remarkably if the shrinkage porosity percent is greater than $1.5 \%$. When the shrinkage rate exceeds $1.5 \%$, not only the mean value of effective modulus decreases, but also the dispersion increases. The experimental results [fivepointed stars in Fig. 18(a)] show that the values fall in the range of the calculated results. Figure 18(b) displays the histogram of $E_{\mathrm{e}}$ : the simulation results distribution covers the range from $145 \mathrm{GPa}$ to $120 \mathrm{GPa}$. The numerical simulation by the improved random lattice model has better predictive capabilities than determinable methods.

The numerical statistical method gives the possible interval of effective modulus, and regarding the error between simulation and experiment, in addition to probabilistic factors, there are two other reasons: (1) the proposed 2D shrinkage porosity model actually is a penetrating type defect, it is the most severe kind of defect. This is a disadvantage of the $2 \mathrm{D}$ model. Therefore, the simulation results are actually a lower

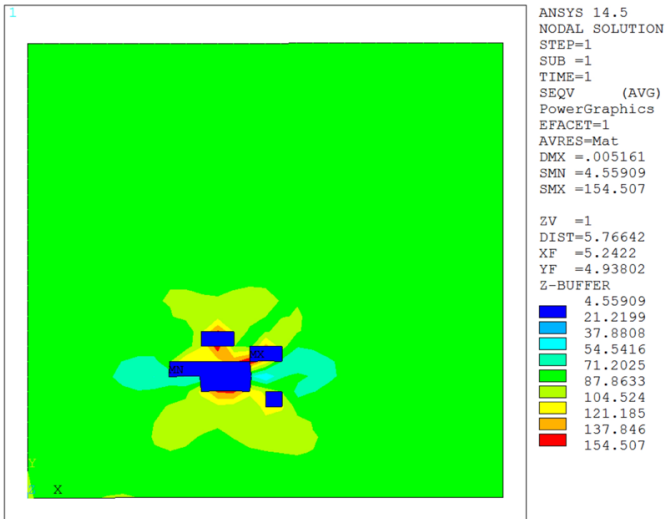

(a) Shrinkage percent: $1.44 \%$

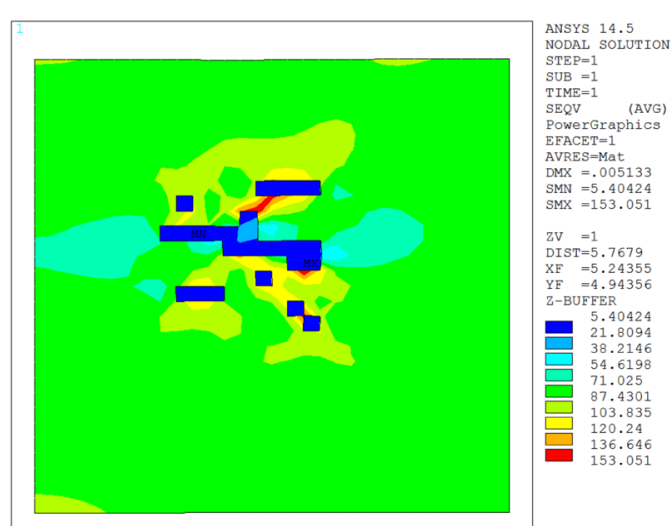

(b) Shrinkage percent: $3.11 \%$

Fig. 15: Stress contour maps of different shrinkage percent samples 

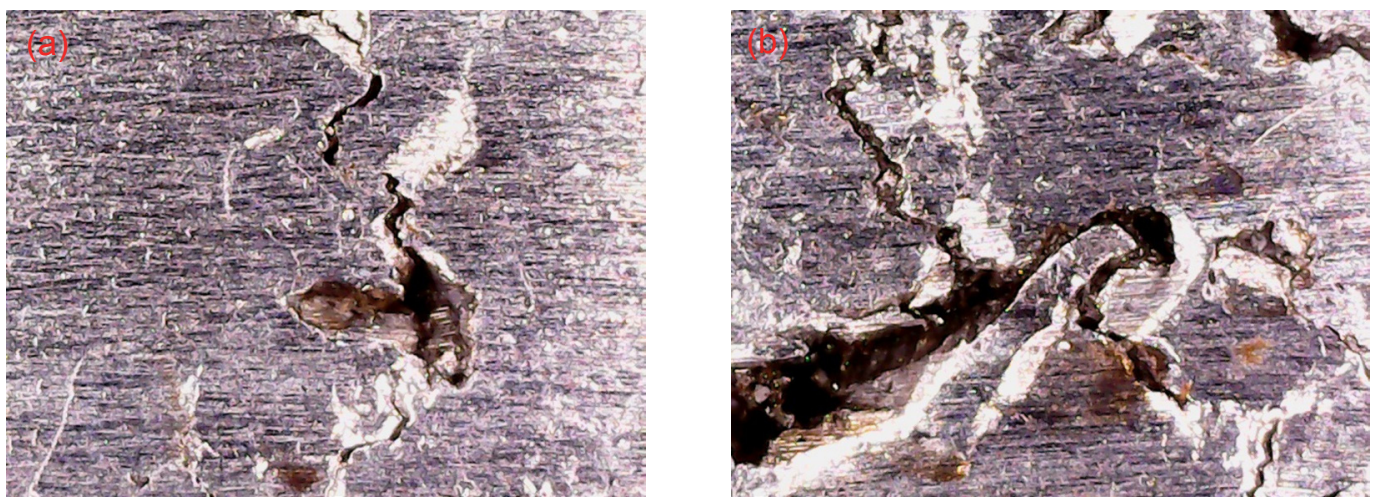

Fig. 16: Micro-cracks and crevasse-cracks nucleate between two shrinkage pores (These cracks connect and accelerate the failure)

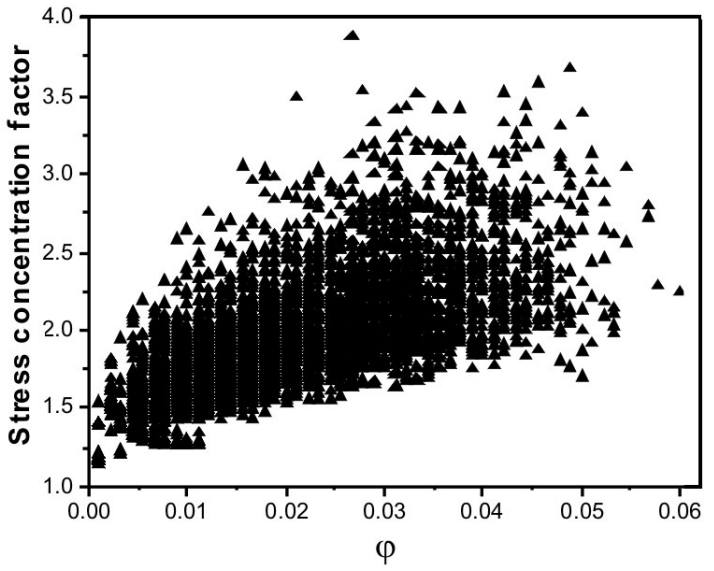

(a) SCF of all numerical samples

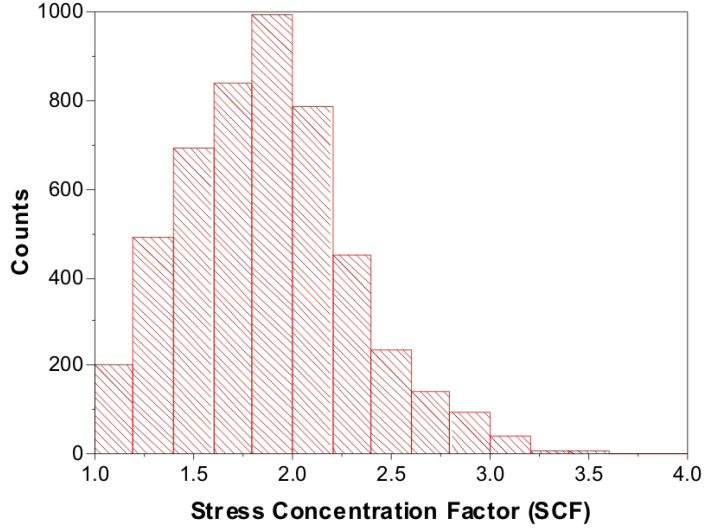

(b) Histogram of SCF

Fig. 17: Distribution of SCF for the samples containing random levels of shrinkage porosity

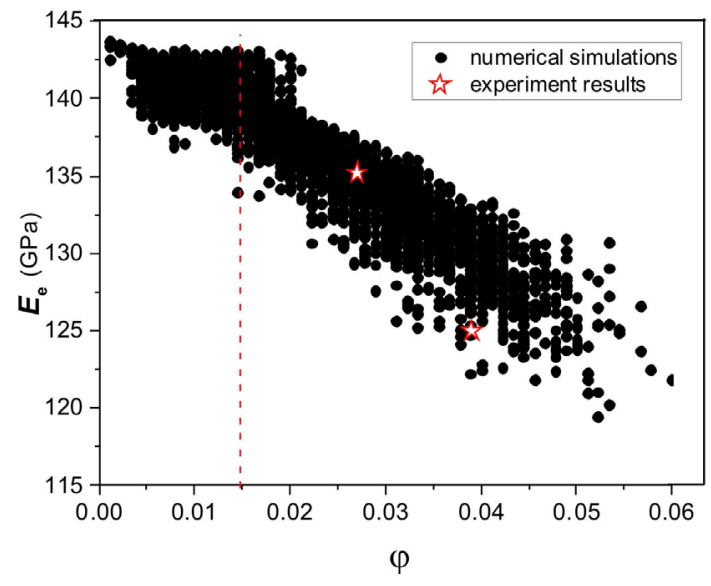

(a) Numerical simulations of $E_{\mathrm{e}}$ and experiment results

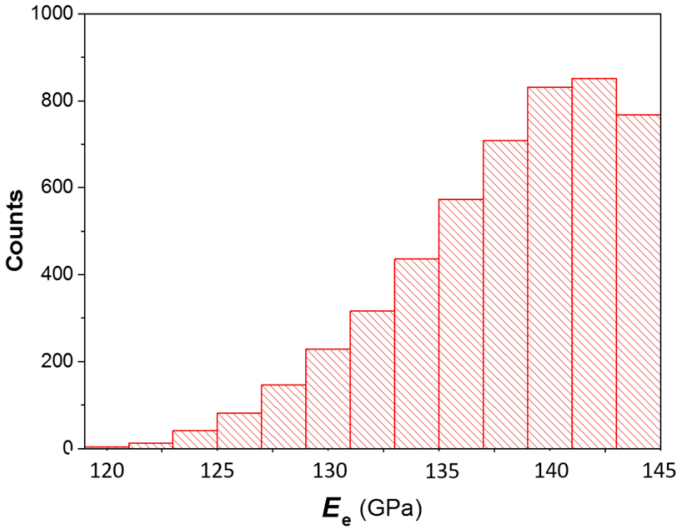

(b) Histogram of $E_{\mathrm{e}}$

Fig. 18: Statistical analysis of effective elastic modulus $\left(E_{\mathrm{e}}\right)$ for the numerical samples, when the shrinkage rate is $0-6 \%$.

bound, so the numerical results are more conservative and safe. (2) The test specimens have a thickness of $5 \mathrm{~mm}$, its internal shrinkage may be more severe or lighter than the surface, which may introduce uncertainty to test results.

\subsection{The shape of shrinkage porosity}

The defect's shape characteristic can be quantified by the length- width ratio of the rectangle envelope $[R(m, n)]$. In order to investigate the influence of a defect's shape on the effective elastic modulus of the random defected sample, a shape factor $\lambda$ is defined to identify the length-width ratio of a random envelope, that is $\lambda=m / n$, where $m$ is the number of elements across the loading direction, and $n$ is the number of elements along the loading direction. In the numerical model, different shape factors can be 
obtained by assigning a proper random sampling number $m$ and $n$, respectively, but maintaining the product of $m$ and $n$ equal. Figure 19 is the sketch diagram of numerical samples containing the same shrinkage percentage. By changing the values of $m$ and $n\left(m_{0} \times n_{0}=m_{1} \times n_{1}=m_{2} \times n_{2}\right)$, their shape factors can be specified but the defect area remains the same.

Here, a square-shaped ( $m_{0}=n_{0}=10$ in Fig. 19) defect region is applied as an example for investigation, its shape factor is 1 . To keep the product of $m_{0}$ and $n_{0}$ equal, its shape can be changed into $m_{1}=5, n_{1}=20$ and $m_{2}=20, n_{2}=5$, and the shape factor $\lambda$ is 0.25 and 4 , respectively. Figure 20 shows the statistical results of effective elastic modulus of numerical samples with the above three shape factors. The scatter points are the simulation results of $E_{\mathrm{e}}$, the box chart and corresponding Weibull distribution curves are also given in Fig. 20. When the length-width ratio of the rectangular region is $1: 1$, the dispersion of the $E_{\mathrm{e}}$ results is larger than other shapes. That is, under the same shrinkage percent, a square shaped defect will introduce more uncertainty than a flat or long shaped defect.

The two parameters for Weibull distribution function, Eq. (6), are applied to fit the above data in Fig. 20; the distribution parameters for the three shape factors are listed in Table 2.

$$
f\left(E_{\mathrm{e}}\right)=\frac{b}{c}\left(\frac{E_{\mathrm{e}}}{c}\right)^{b-1} e^{-\left(\frac{E_{\mathrm{e}}}{a}\right)^{b}}
$$

where $c$ is the scale parameter, $b$ is the shape parameter for the Weibull distribution function. The effective elastic modulus decreases with the shape parameter increasing, it drops more sharply if the shape factor is greater than 1 . That means, for the shrinkage porosity regions with the same area, the defect's length across the loading direction plays a more important role in the effective modulus.

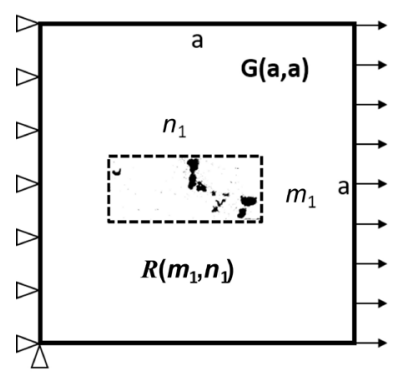

(b) $\lambda=\frac{m_{1}}{n_{1}}<1$

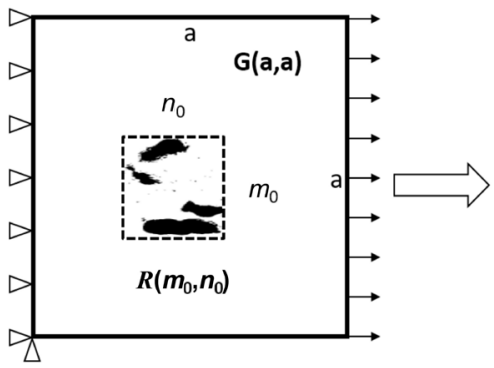

(a) $\lambda=\frac{m_{0}}{n_{0}}=1$

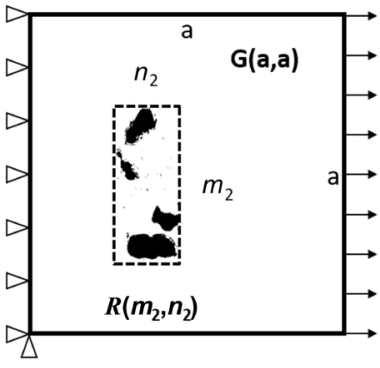

(c) $\lambda=\frac{m_{2}}{n_{2}}>1$

Fig. 19: Shape factors of rectangle envelope can be specified but the defect area stays approximately the same

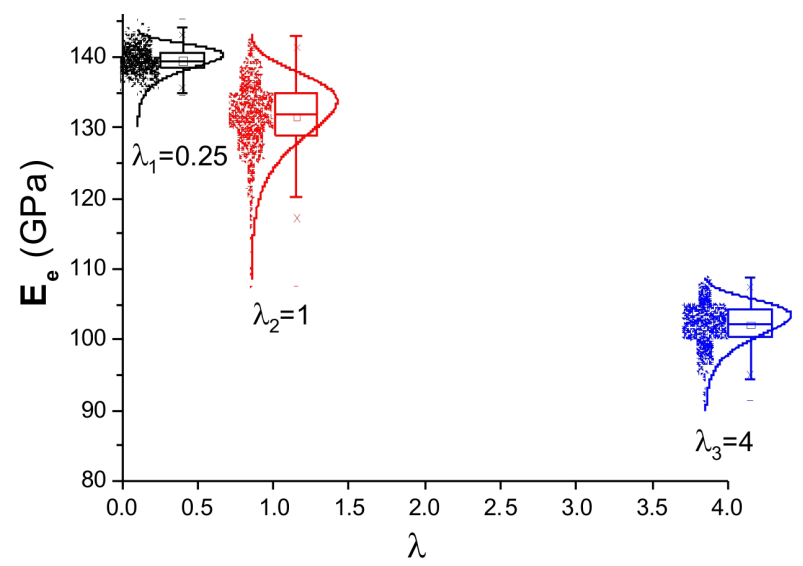

Fig. 20: Box chart of effective elastic modulus $\left(E_{\mathrm{e}}\right)$ of numerical samples with different shape factors (the mean porosity rate is $3.46 \%$ )

Table 2: Distribution parameters of Weibull function for $E_{\mathrm{e}}$ of numerical samples with different shape factors

\begin{tabular}{cccc}
$\begin{array}{c}\text { Weibull distribution } \\
\text { parameters }\end{array}$ & $\boldsymbol{\lambda}=\mathbf{0 . 2 5}$ & $\boldsymbol{\lambda}=\mathbf{1}$ & $\boldsymbol{\lambda}=\mathbf{4}$ \\
Scale parameter & 140.4 & 133.9 & 103.5 \\
Shape parameter & 93.4 & 45.0 & 29.2 \\
\hline
\end{tabular}

\subsection{Relative position of shrinkage porosity}

The defect occurs in any location of the casting, and the randomness of shrinkage porosity is also reflected on the position. Taking a random defect specimen for example, as shown in Fig. 21, the position of a defect region can be identified by four parameters, the parameters are expressed by the symbols $d_{i}(i=1,2,3,4)$. Here, $d_{1}$ and $d_{2}$ are the two distances from the boundary of the defect envelope to the surface of

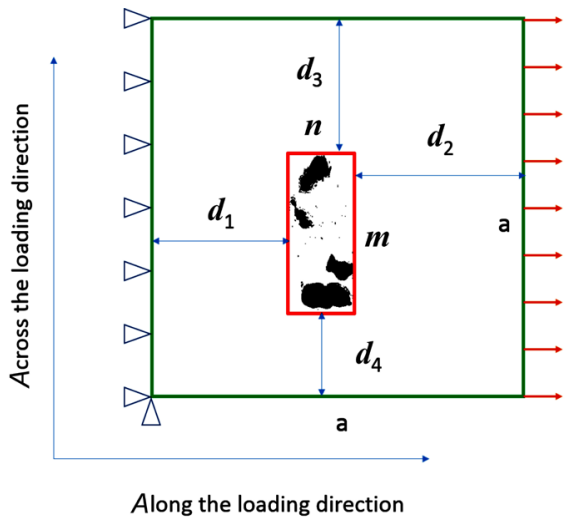

Fig. 21: Position of a defect region can be identified by $d_{i}(i=1,2,3,4)$ 


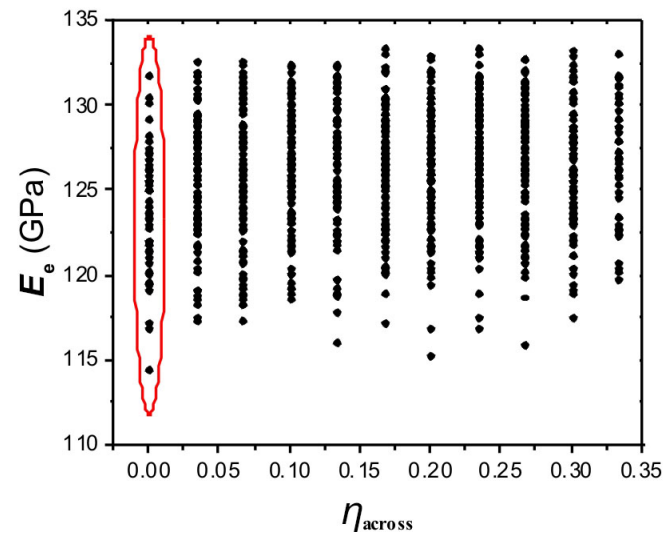

(a) Relative position factor across the loading direction

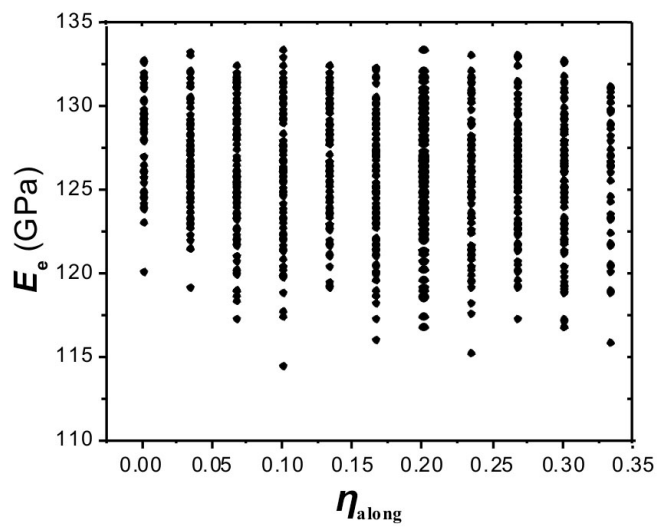

(b) Relative position factor along the loading direction

Fig. 22: Effective elastic modulus $\left(E_{\mathrm{e}}\right)$ of numerical sample with different relative positions (the mean porosity rate is $3.42 \%$ )

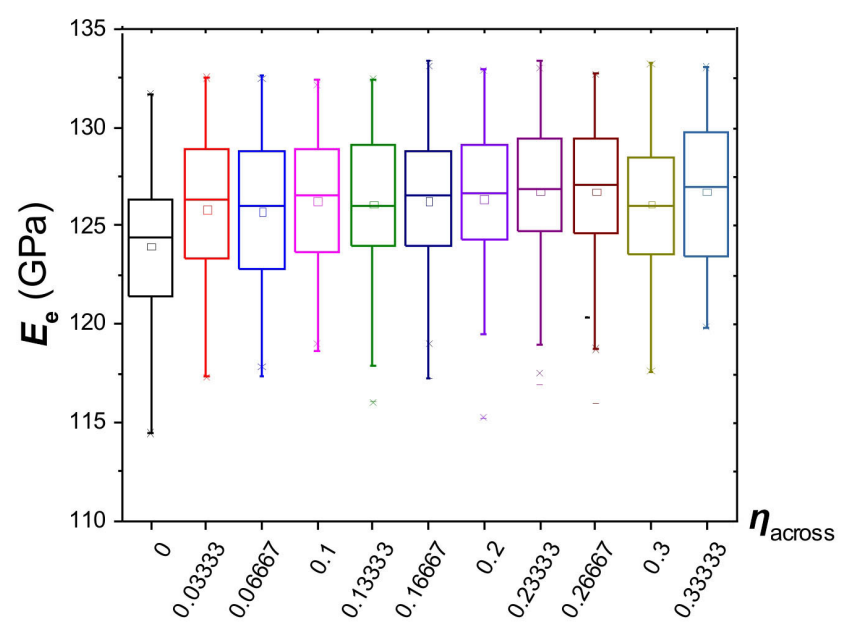

Fig. 23: The mean of $E_{\mathrm{e}}$ with surface defect is lower than the mean of whole numerical samples by about $1.5 \%$

the specimen along the loading direction, $d_{3}$ and $d_{4}$ are the two distances from the boundary of the defect envelope to the surface of the sample across the loading direction. Its relative position in the whole samples can be simplified as $\eta=d_{\mathrm{i}} / a$, it denotes nondimensional relative position of the defects in the casting. Here, to simplify the analysis, the shortest distance from the defect to the surface $\left[d_{\mathrm{i}}\right]_{\min }$ is applied to characterize the unique position of the shrinkage porosity defect, so the relative position factor $\eta$ along the loading direction and across the direction is defined as $\eta_{\text {along }}=\left[d_{1}, d_{2}\right]_{\mathrm{min}} / \mathrm{a}$ and $\eta_{\text {across }}=\left[d_{3}, d_{4}\right]_{\mathrm{min}} / \mathrm{a}$, respectively (as shown in Fig. 21). The values of $\eta$ can be collected from every numerical sample, and its relations between the effective elastic modulus are plotted in Fig. 22 (the rectangle envelope is $m \times n=10 \times 10$ ). It can be seen that the effective modulus $\left(E_{\mathrm{e}}\right)$ is not sensitive to the position of shrinkage porosity defect in a casting, but compared with the other position defects, the surface defect across the loading direction (Fig. 22(a) $\eta_{\text {across }}=0$, that is $d_{3}=0$ or $d_{4}=0$ ) has a significant effect on reducing stiffness. Figure 23 shows box chart of the data in Fig. 22(a), the mean value of $E_{\mathrm{e}}$ with surface defect is lower than the mean of the whole numerical samples by about $1.5 \%$.

\section{Conclusions}

An improved random lattice model was proposed to describe the special random configuration of shrinkage porosity. Based on statistical methods, the influences of defect characteristics such as size, shape, position, and material performance on the macroscopic equivalent modulus of castings are analyzed. The following conclusions can be drawn from the investigation:

(1) Maximal stress often occurs at the site of larger area pores or the site between two pores. The micro-cracks and crevassecracks nucleate between two shrinkage pores firstly. These cracks connect and accelerate the failure, it is an important reason for the fall of ductility of casting containing shrinkage porosity.

(2) The effective elastic modulus of defect casting decreases remarkably if the shrinkage porosity percent is greater than $1.5 \%$.

(3) The average SCF caused by shrinkage porosity is about 2.0 .

(4) The defect's length across the loading direction plays a more important role in the effective modulus than the length along the loading direction.

(5) Surface defect across the loading direction reduces the mean value of effective modulus by about $1.5 \%$ over the defect of other positions.

\section{References}

[1] Hardin R A, Beckermann C. Effect of porosity on deformation, damage, and fracture of cast steel. Metallurgical and Materials Transactions A: Physical Metallurgy and Materials Science, 2013, 44(12): 5316-5322.

[2] Wang $Z \mathrm{H}$, Zhao $\mathrm{W} \mathrm{H}$, Zhou $\mathrm{Z} \mathrm{H}$, et al. Effect of shrinkage porosity on mechanical porosities of ferritic ductile iron. China Foundry, 2013, 10(3): 141-147.

[3] Collini L, Pirondi A, Bianchi R, et al. Influence of casting defects on fatigue crack initiation and fatigue limit of ductile 
cast iron. Procedia Engineering, 2011, 10: 2898-2903.

[4] Murakami Y. Metal fatigue: effects of small defects and nonmetallic inclusions. Elsevier Science Ltd., Oxford, 2002.

[5] Coble R L, Kingery W D. Effect of porosity on physical properties of alumina. Journal of the American Ceramic Society, 1956, 39: 377-385.

[6] Gibson L J, Ashby M F. The mechanics of three-dimensional cellular materials. Proceedings of the Royal Society A, 1982, 382: 43-59.

[7] Rice R W. Evaluation and extension of physical propertyporosity models based on minimum solid area. Journal of Materials Science, 1996, 31: 102-118.

[8] Kordkheili Hosseini S A, Toozandehjani H. Effective mechanical properties of unidirectional composites in the presence of imperfect interface. Arch. Appl. Mech., 2014, 84:807-819.

[9] Parsaee A, Shokrieh M M, Mondali M. A micro-macro homogenization scheme for elastic composites containing high volume fraction multi-shape inclusions. Computational Materials Science, 2016, 121: 217-224

[10] Sakata S, Ashida F, Kojima T, et al. Three-dimensional stochastic analysis using a perturbation-based homogenization method for elastic properties of composite material considering microscopic uncertainty. International Journal of Solids and Structures, 2008, 45(3-4): 894-907.

[11] Wu Y Z, Dui G S, Zhu Y P. An approximate solution for the effective elastic moduli of differential method. Chinese Journal of Solid Mechanics, 2011, 32(3): 282-286.

[12] Tijani Y, Heinrietz A, Atets W, et al. Detection and influence of shrinkage pores and non-metallic inclusions on fatigue life of cast aluminum alloys. Materials Properties, Characterization, and Modeling, 2012(2): 225-232.

[13] Gao Y X, Yi J Z, Lee P D. et al. The effect of porosity on the fatigue life of cast aluminium-silicon alloys. Fatigue \& Fracture of Engineering of Materials \& Structures, 2004, 27(7): 559570.

[14] Cao X B, Zhao J, Fan J H, et al. Influence of casting defects on fatigue behavior of A356 aluminum alloy. International Journal of Cast Metals Research, 2014, 27(6): 362-368.

[15] Wan Qian, Zhao Haidong, Ge Jilong. Effect of micro-porosities on fatigue behavior of aluminum die castings. The Chinese
Journal of Nonferrous Metals, 2015, 25(3): 568-574.

[16] Hardin R A, Beckermann C. Effect of porosity on deformation damage and fracture of cast steel. Supplemental Proceedings: Material Properties, Characterization and Modeling TMS (The Minerals, Metals and Materials Society), 2012.

[17] Mo D F, He G Q, Hu Z F, et al. Crack initiation and propagation of cast A356 aluminum alloy under multi-axial cyclic loading. International Journal of Fatigue, 2008, 30: 1843-1850.

[18] Liu W, Zhai W H, Zhao J F. Influence of Shrinkage Porosity on the Fatigue Performance of Casting and the Life Estimation Method. China Foundry, 2016, 13(1): 47-53.

[19] Sevostianov I. On the shape of effective inclusion in the Maxwell homogenization scheme for anisotropic elastic composites. Mechanics of Materials, 2014, 75: 45-59.

[20] Lennon A B., Prendergast P J. Modeling damage growth and failure in elastic materials with random defect distribution. Mathematical Proceedings of the Royal Irish Academy, 2004, 104A(2): 155-171.

[21] Fjeldstad A, Wormsen A, Harkegard G. Simulation of fatigue crack growth in components with random defects. Engineering Fracture Mechanics, 2008, 75(5): 1184-1203.

[22] Karlen $\mathrm{K}$, Olsson $\mathrm{M}$, Ahmadi $\mathrm{H}$, et al. On the effect of random defects on the fatigue notch factor at different stress ratios. International Journal of Fatigue, 2012, 41(8): 179-187.

[23] Hassold G N, Srolovitz D J. Brittle fracture in material with random defects. Physical Review B Condensed Matter, 1989, 39(39): 9273-9281.

[24] Cosmi F. A cell method model for sintered alloys. Computer Modeling in Engineering \& Sciences, 2011, 74(4): 269-282.

[25] Chen $Y$ Q, Zheng $X P$, Yao $Z \mathrm{H}$, et al. Application of lattice model and statistical methods in analyzing equivalent macromechanical properties of two-phase materials. Acta Mechanica Solida Sinica, 2001, 22(4): 394-402.

[26] Feng W G, Yang X H, Chen C Y. Analysis of effective macromechanical properties of heterogeneous elastic isotropic materials with normal distribution. Journal of Mechanical Strength, 2008, 30(1): 132-136.

[27] Eshelby J D. The determination of the elastic field of an ellipsoidal inclusion and related problems. In: Proceedings of the Royal Society, London, Series A, 1957, 240: 367-396. 